\title{
Textual Research on Building Groups of Sanyi Temple in Henan
}

\author{
Haiting Jia \\ Jiaozuo Teachers College, Jiaozuo, 454000, China
}

\author{
Keywords: Sanyi Temple, Buildings, Structure, Pattern
}

\begin{abstract}
Wushe, Henan has a profound historical and cultural deposition, and the Taoist buildings in Sanyi Temple have distinctive characteristics. On the basis of more surveys, the construction history, building characteristics and building decoration of main buildings of Sanyi Temple are examined and analyzed and it is found that they belong to the buildings with official style in the Qing Dynasty with the Taoism, and they can be taken as a representative of the official-style buildings in Qinhuai region in the Ming and Qing Dynasties.
\end{abstract}

\section{Introduction}

Wushe County, located in the northwest of Henan, separated from the capital city Zhengzhou by river, is the south gate of Jiaozuo. Wushe has a long history, belonging to Jizhou in the Xia Dynasty, called Qinhuai and Huaiyi at the beginning of the Zhou Dynasty. In the $26^{\text {th }}$ year of the period of the First Emperor of the Qing Dynasty (221 BC), after unity, Huaixian County was established. China is a country with more religions, most of the existing religious buildings in Wushe are Taoist temples and Buddhist temples. The religious building groups in Wushe generally consist of drama stages, gate of monastery, main palaces and wing rooms. The overall layout is centered on the central axis and symmetrical construction on the left and right. Generally, the layout of the traditional Chinese buildings follows the basic principle of "superior and subordinate" of the Confucianism and "men superior to women". There is a stress of symmetry of central axis on the left and right, the main buildings are arranged on the central axis, while the auxiliary buildings are on the sub-axis. According to Book of Diverse Crafts of the Rites of Zhou, "The capital constructed by the craftsmen is $9 \mathrm{Li}$ in area, with three gates on each side, there are 9 roads in the longitudinal and transverse directions with the north-south road 9-track wide. The east is the ancestor temple, west is Altar of Land and Grain, the front is the king's resting place, behind is market and dwellings, and the imperial court has an area of 100Mu.” It can be seen that the building layout of central axis symmetry had been adopted at that time, with palace located on the central axis. According to the description in Situation Judgment of Mister Lyu's Spring and Autumn Annals, "the country is established in the center of the world, and palaces are built in the center of the country", meaning that "center" was the most respected direction. Therefore, although the religious buildings remaining in Wushe have been ruined in wars, according to the current status, the building group characteristics of central axis layout can be fully demonstrated.

\section{Building analysis}

Dafeng Sanyi Temple is located in Zhaozhuang Village, Dafeng Township 20km away from the southwest of Wushe County. According to Wushe County Annals in the $9^{\text {th }}$ year of Emperor Daoguang, "Sworn Temple is in Zhaozhuang", so it can be seen that Saiyi Temple was also called "Sworn Temple" during the period of the Emperor Daoguang. Dafeng Sanyi Temple enshrines Guan $\mathrm{Yu}$, Liu Bei and Zhangfei and it is also called "Temple of Guan Yu" locally. It is unknown when Sanyi Temple was first built, according to the inscriptional record of The Ming Dynasty, it was reconstructed, so it can be speculated that it was built in or before the Ming Dynasty. In the existing ancient building, there is one main palace, the gate to the monastery and rear palace were restored on the original site, both of them face the south and are against the north, with basically complete group. According to the inscriptional record of Wushe County People's Government about Sanyi Temple, 
Sanyi Temple is located in Zhaozhuang Village, Dafeng County 20km away from the southwest of Wushe County. The existing buildings include one main palace, being a building of single eve and overhanging gable roof type, with three in width and three in depth. The ridge lip treasured vase at the top of the palace is of colored glaze decoration, with dragon and phoenix patterns, rare in the world. It is of grey cylinder pan tile ceiling structure, under the eave is five-stamping high bracket. The nose is carved with dragon head, below are plate square column and major beam, with seven-purlin structure, the central bay in the front is plate room, with meticulously carved stone drum gate pier. The end bay is of lattice structure, and there is an obvious side angle in the beam. Because of being out of repair for long years, the Buddha statute in the original building was overthrown, and in the $9^{\text {th }}$ year of the period of Emperor Hongzhi in the Ming Dynasty, it was rebuilt. Four 517 years, it had been repaired for 5 years, the wall and wood materials remained unchanged. The existing auxiliary cultural relics included four tablets of the Ming and Qing Dynasties, which were all the inscriptional records of the repair of Sanyi Temple. In addition, there are three iron censers built in the third year of the 9th year of Emperor Hongzhi in the Ming Dynasty.

Since the Tang Dynasty, the stories about Sanyi Temple had been recorded. During the Three Kingdoms Period, Liu Bei, Guan Yu and Zhang Fei defeated Lyu Bu in Hulao Pass and rested here, so the local people built the temple for worship, the original statue in the temple was Liu Bei, and was destroyed in 1950, there was the horizontal inscribed board Excellent Shrine in the original building written by Wang Xizhi, calligrapher of the Eastern Jin Dynasty, Yue Fei's father in the Southern Song Dynasty wrote the inscribed board Overawing Rivers and Mountains, and there were also gate to monastery, horse tying pavilion and eastern and western bungalows, which were demolished in the 1960s. At present, there is a main palace, with simple building form, high artistic and cultural value, being a precious historical and cultural relic. Wushe Count People's Government emphasizes the cultural relic protection very much and announced that it was one of the second group of cultural relic protection sites of Wushe County in May 1995 and stipulated that everyone should be responsible for protecting the cultural relics.

The main palace of Sanyi Temple is the main building of the temple, with three rooms in width (1110 cm, outer edge distance of building, the same below), and 6 in depth $(766 \mathrm{~cm})$, being a single-eave overhanging gable roof and five-ridge building. The central bay is $342 \mathrm{~cm}$ wide (central distance between two columns, the same below), the side bay is $278 \mathrm{~cm}$, both sides are stepped gable walls, the external wall is built with black bricks, and the inside is built with earth, and the wall in the room is plastered with limestone. The gable wall is $100 \mathrm{~cm}$ thick. The floor is paved with black bricks, there is a solid gate in the middle of the wall in front of the palace, with a width of $190 \mathrm{~cm}$, red, without nail, there are four flower patterns on the door and drum-shaped bearing stones are placed on both sides of the gate. The roof at the top of the palace is paved with grey pan tiles, with green and yellow colored glaze cylindrical tiles. The eaves on the front and rear ends of the palace top are edged with yellow colored glaze tiles, totally 48 and there are 47 triangle-shaped edges. The eaves tiles at the end and the triangle-shaped edges are both of dragon shape, both are of printed patterns, and on the eave tiles, there are well preserved yellow colored glaze tile nail heads. The whole ceiling is preserved well, the top of the main ridge is covered with green colored glaze cylindrical tiles, and on both ends of the main edge are ornament of legendary animal, which was said to be one of the nines sons of the dragon, and Li Dongyang in the Mind Dynasty in the amendment About Nines Sons of Dragon of Huailu Tangji recorded its story. Because of such legendary animal was liked climbing, could spray water and loved swallowing water, people often placed its image on both sides of the main ridge for fire avoiding. The ornament of such legendary animal in the main palace of Sanyi Temple is a yellow colored glaze product, which swallows the main ridge from both sides, and there are two small dragon heads respectively swallowing the vertical edge in the front and back, and this is also the unique decoration of ancient religious buildings in Qinhuai Region, "a kiss with three heads". This building is relatively small in form, so the two heads in the front and at the back in the three heads have sufficient volumes obviously. The modeling of the front kissing contains all body parts of the dragon in the legend, the dragon opens its mouth large, lifts its tongue in the front, the sharp teeth have distinctive modeling, the extrusion shaped by the dragon teeth might be related with the folk 
legend that dragon teeth could exorcise evil spirits, and people hoped that the sharp dragon teeth high above could avoid all evil spirits, the dragon noses is warped high, indicating the acute sense of smelling and momentum of dragon. The dragon eyes are opened angrily, representing that the dragon could observe all, the dragon eyes were made very vividly, consisting of the eye white and black eyeball, the black eyeball is black glass ball, making the dragon eye brimming with radiating power, threatening all evils, and the dragon eyes are covered with eyebrows of curling grass pattern. The dragon ear is clairaudience, so eiyanthe modeling is generally backward drifting, representing that the dragon could hear the remote sound, on both sides of the dragon ear, bristle and eyebrow are connected together, carved into curing glass pattern. The clear and visible dragon beard strengthens the majesty of the dragon. The dragon body is warped upwardly and curved internally, like a flower roll, with the technique of high relief, the head, eye and beard are all very exquisite. The whole dragon is dotted with several clouds in the surrounding area, making the picture more complete. There is also a lotus-shaped sword handle inserted in the dragon body. It was said that this sword belonged to the immortal Xu Xun in the Jin Dynasty, and it has three roles: one is to prevent the legendary animal escaping, so that it can spray water to prevent fire for the building; the second is that according to the legend, the devils were most afraid of the sword of $\mathrm{Xu} \mathrm{Xun}$, and when seeing it, they would escape, meaning exorcising evil spirits; and third, the legendary animal pattern generally consisted of more colored glaze elements, and the sword handle plays a role of fixing in the structure of the legendary animal. The placement of the front kissing showed the awing of the Chinese people to the gods, love to buildings and eulogizing to life for thousand of years.

In front and at the back of the main ridge are both dragon pattern. There is a pagoda top and waist flower pattern in the middle of the main ridge, the pagoda top is of two-layer calabash modeling, and the waist flower pattern consists of two dragon-shape kissing animals with the reverse directions, the dragon opens its mouth large to swallow the main ridge on both sides, and centered on the waist flower pattern, there are three flowing dragons with different modeling on both sides, with ball playing action to the central point of the main ridge. The top of the vertical ridge is also covered with green cylindrical tiles, both the inside and outside are of peony patterns and there is a hanging animal pattern at the end, which is also yellow colored glaze, raising its head and looking far. The vertical ride extends to about $2 / 3$ of the roof, and there is a side angle (simple angle ridge), the end of which is decorated with ridge angle animal. The ridge angle animal is of abstract and simple modeling, with an arc upward bucket angle shape. There is a platform built in front of the palace, with the same width and depth, 336cm deep and 72cm high, due to the change of terrain in the modern times, the platform is high in the east and low in the west. The platform is paved with black bricks and the middle is paved with four-level fire reel step with stepping up and down.

The main palace of Sanyi Temple is of seven-frame and no-gallery form. The front and rear gold columns are red painted and the building is of enwrapped column structure. The column top supports the plate tie beam, and both ends of the tie beam are inserted into the gabled roof on both side, the plate tie beam is attached to the architrave below, and connected to both columns and gabled roofs on both sides. The plate tie beam is installed with five-stamping brackets, with 8 brackets in front and seven at the back, in which the two between the two gold columns in front are two bracket sets between columns, while there is only one between the gold columns of the rear wall. The nose carving of the bracket set on columns in the front is a dragon head, and the others are of ordinary molding. Seven-frame beam is supported above the oval arm in the center of the brackets. There is an eave tie beam below the eaves purlin. Both the eaves purlin and eave tie beam are of three-segmentation wood material connection, with the interface located on both sides of the bracket, and both sides of the purlin are inserted into the gabled roof. There is an eave rafter and flying rafter under the eaves. Although the main palace of Sanyi Temple is not high in greade and the structure is simple, the two-layer rafters in front of the eaves greatly highlight the depth of the eaves, and the four corners of the roof are warped significantly, with very significant characteristics of curve beauty of the traditional architecture. The purlin is paved with circular eave rafter, with bricks on the rafter. The backing plate and eave tie beam are drawn with colorful painting in front. The king post above the central bay in the room is short and small, and ridge tie beam is supported on the king post, below the 
ridge tie beam is wood rod, which penetrates the body of king post. A bracket is installed between the ridge purlin ane ridge tie beam, and there are two brackets between each column. There is a V-shaped brace placed on the three-purlin beam, the end of the V-shaped brace is a hemp leaf head, which intersects with the bracket in the ridge purlin. The ridge purlin is closely attached to the ridge purlin, and the beam head interests at the top of the bracket. A gold purlin is installed on the three-purlin gold purlin, the upper gold purlin is closely attached to the flitch, inserted into the body of the three-purlin beam. The five-purlin beam supports the lower gold purlin, and the purlin is also closely attached to the flitch below, and two brackets are on the lower gold purlin and lower gold tie beam between two columns. Both ends of the lower gold purlin are inserted into the lower gold column. Both ends of the seven-purlin beam are respectively erected on the top of the front and rear gold columns. Due to functional difference of the temple groups, the construction specification and relation between primary and secondary must be distinguished. The main palace is the core building in the whole temple building group, so the roof is a single-eave hanging gable roof five-edge roof building. Although the hanging gable roof modeling is of no high grade and the roof is not high, it is the most solemn and splendid roof form in the area with ordinary economic condition, and such roof is not allowed to be used in the ordinary dwellings and temple wing rooms and worship palace. Furthermore, these do not reduce the sense of beauty of the buildings. There is high platform and broad steps under the homestead, although they are of simple modeling, they can increase the sense of towering of the buildings. Besides, with a simple structure, there is no lack of characteristic of curve beauty of buildings. The wood structure of the gate palace is of elevated beam construction method to strive for the maximum indoor area on the limited construction area. The roof of the gate palace is paved with black cylindrical tiles, which are cylindrical tile blanks and are halved from the cross section to present a semicircle. In the traditional buildings of China, cylindrical tiles have a higher grade than pan tiles. In various periods of the feudal society, cylindrical tiles were more used for the building roof of the superior officials or the officials with level higher than the superior officials, and were not allowed to be used for the ordinary dwellings, and it was only until the founding of the PRC that this traditional rule was broken. In the ancient times, cylindrical could be only be only used for the palaces, temples or other high-grade buildings, and this also manifested the special status of this building, namely the temple. The simple use of cylindrical tiles for roof would make people awed remotely. The gate palace is higher than the overall height of the round-edge-roof worship palace, but lower than the master palace of the main palace, because although the round-edge-roof worship palace has a large area, there is no god statute in it, but only the space for worship Buddha. The roof of the main palace is of five-ridge form, and the roof of the worship palace is generally round ridge roof, i.e., there is no ridge, while the ordinary wing room is of single ridge form, i.e., there is one ridge. All these designs highlight that the main palace has the highest status in the temple building. The actual role of the ridge is to avoid rainwater penetrating along the tile gap, and generally ridge is the highest point of the roof, and the part when people first see, so this par is also the most important decoration part in the ridge.

Both sides of the gate of Sanyi Temple are drum-shaped bearing stones, $84 \mathrm{~cm}$ high, $30 \mathrm{~cm}$ thick and $57 \mathrm{~cm}$ wide, with large volume, saturated modeling and luxurious carving. Only the front and internal side of the drum-shaped bearing stones can be seen, and the other parts cannot be seen because they are built in the wall. The drum-shaped bearing stones are divided into three parts, the upper is a circular stone drum, lower is square pedestal and rear is the gate support. There are animal patterns on both of the two drum-shaped bearing stones, but they have been seriously damaged, it is speculated that the two animals should be a large and small lions, the small lion was in the front, naughty and cute, and the large one behind. The front part above the stone drum is plant pattern, the western pattern is chrysanthemum, the head of which is located in the middle, and the surrounding are chrysanthemum leaf, with vivid modeling. The east are three lotus flowers, with beautiful gestures. The side picture includes two persons, one riding a horse with a follower. The edge of the stone drum is carved with nail modeling. The upper part is connected to the lower part with a wish seat, the front which is a Chinese dragon, and the Chinese dragons on both sides face each other. The lower pedestal is of draping pattern, and the center of the drape are circulars. The contents of the front circular are 
texts, the east is a character of blessing and the west wealth. The contents of the side circular are animal patterns, the east is a phoenix and the west dragon, meaning good luck. The whole stone drum is carved with flower patterns, extremely beautiful.

\section{Conclusion}

Although only the main palace of Sanyi Temple was an ancient building, the gate and rear palace respect the history, and were rebuilt on the original site, and second, the pattern and specification were recovered completely according to the original building, the wood materials of the main beam were the original building members, so the building group was not damaged overall, and the recovering the complete temple group is beneficial for the balanced layout. The whole building is of layout along the central axis, with strict symmetry on the left and right. There are more buildings with complete pattern and clear primary and secondary levels, and the building forms are diversified, which cab basically represent the characteristics of Taoist buildings in Qinhuai region in the Ming and Qing Dynasties.

\section{References}

[1] Liang Sicheng, Rules for Construction of Qing-style Buildings, Tsinghua University Press, 2006

[2] Liang Sicheng, Volume 7 of Collection of Liang Sicheng, Notes of Construction Method, Beijing: China Architecture \& Building Press, 2001

[3] Bai Lijuan, Wang Jingfu, Wood Structure of Qing-style Buildings, Beijing: China Building Material Industry Press, 2007

[4] Liu Dunzhen, History of Ancient Buildings of China, China Architecture \& Building Press, 2007

[5] Liu Dake Stone Construction Method in Ancient Buildings of China, Beijing: China Architecture \& Building Press, 1993

[6] Lou Qingxi, Carved Beams and Painted Pillars, Beijing: Tsinghua University Press, 2011

[7] Qing Dynasty, Wang Chu Huangpu Family Tree, written in the 46th year of Emperor Qianlong (1781)

[8] Qing Dynasty, Wang Tong Henei County Annals, 5th year of the Emperor Daoguang (1825) photocopy, Taipei: Chengwen Publishing House Co., Ltd., 1976z 